\title{
La crisis como oportunidad \\ Grupos intelectuales y la construcción del Estado post- \\ -revolucionario: su contexto político e intelectual (1934-1950)
}

Lidia Girola

Introducción

El objeto de este trabajo es proporcionar un panorama del contexto político e intelectual de los años de construcción del Estado mexicano y algunas importantes instituciones y empresas culturales, después de la Revolución. Espero mostrar la relación entre los distintos gobiernos, y diferentes grupos de intelectuales en el periodo, y cómo se dio algo que es característico de México y que quizá lo diferencie de otros países en América Latina: la profunda imbricación entre los gobiernos posrevolucionarios y la participación de los intelectuales en cargos tanto académicos, como técnicos y políticos.

Intento asimismo, mostrar las diferencias y similitudes entre diversos grupos, tanto por sus intereses y ambiciones, como por el papel que le dieron al conocimiento $\mathrm{y}$ a las diferentes formas de construirlo.

Si bien la historia es un continuo, y hablar de un determinado periodo supone hacer un corte temporal en cierto modo arbitrario, lo que propongo es tomar los años que van desde mediados de los años treinta, a finales de la década de los años cuarenta, en el entendido de que es en esos años en los que se produjeron luchas políticas en las que se definió el derrotero de México, y que afectaron a la constitución de instituciones y empresas culturales en el país.

La historia de México es, entre otras cosas, la historia de sus sucesivas y pero también las consecuencias de varias situaciones críticas por las que pasaba la socie- 
dad mexicana, décadas después de la Revolución Mexicana iniciada en 1910, que sin embargo continuó como ideal normativo revisado y re-significado a lo largo del tiempo y especialmente en el periodo materia de este trabajo.

La historia del México post-revolucionario también puede organizarse en segmentos sexenales, en los que se reflejan los cambios que cada Presidente impulsa en el tiempo de su mandato, y que muestran, a pesar de la continuidad del partido en el poder, los diferentes énfasis, proyectos y decisiones que cada mandatario impuso en su gobierno.

Quiero desde el inicio aclarar que el concepto de crisis que voy a utilizar aquí, se refiere a situaciones de cambio, de necesidades nuevas, de carencias que fuerzan a la innovación y a la imaginación. Cuando hablo de crisis no me refiero sólo a cuestiones negativas de colapso y riesgo, sino a las oportunidades que situaciones inesperadas o al menos no buscadas, generan en las sociedades y en la vida de las personas; también, a las consecuencias de acciones que tienen un propósito más o menos explícito, en un área determinada, pero tienen repercusiones en otros campos. En el proceso de constitución de una nación joven, nueva y compleja, es común la recurrencia de las situaciones de crisis; tanto las que surgen por el choque de facciones, por la contraposición y el paulatino desgaste de los diversos proyectos de nación, por los errores o ineficiencias en la implementación de políticas; como las ocasionadas por situaciones externas, como pueden ser las presiones internacionales o las guerras, aunque éstas sean relativamente lejanas.

¿Nacionalismo, socialismo, populismo? El gobierno de Lázaro Cárdenas (1934-1940)

Específicamente, desde mediados de la década de los años 30, a fines de la de los años 40 del siglo $\mathrm{xx}$, varias crisis, en lo que tienen de riesgo, pero también como oportunidades, se cernían sobre la sociedad mexicana. Una de las principales, fue la del desgaste del ideario de la Revolución Mexicana, acompañada por circunstancias graves en el ámbito financiero en 1937 y los reacomodos necesarios después de la expropiación petrolera del año 38. Si el gobierno cardenista mostró un claro interés por el reparto agrario (uno de los objetivos de la Revolución); la disminución de la desigualdad, y el empoderamiento de los sectores obrero y campesino, a fines de su mandato, el general Cárdenas enfrentó serios problemas en todos los frentes: el descontento empresarial, las sospechas de Estados Unidos con respecto a sus políticas "socialistas" y la insistencia de los norteamericanos para que México pagara las compensaciones que consideraban adecuadas a las empresas petroleras expropiadas; las dificultades para borrar la inequidad entre las condiciones de vida de los distintos sectores de la población, el atraso educativo. La transición entre un Presidente y otro, 
suponía indefectiblemente momentos de tensión y temores ante los candidatos no elegidos por el Partido y/o el presidente saliente, que muchas veces significaban el riesgo de conflicto armado. La democracia representativa nunca fue un ideal de todos los revolucionarios ${ }^{1}$, y ya con Cárdenas lo que se instrumentaba era un modelo corporativista y dirigido verticalmente por los sectores que detentaban el poder político.

La política educativa y cultural de Cárdenas fue intensa, centrada sobre todo en la alfabetización de los indígenas y campesinos, a través de la creación de escuelas rurales que se proponían no sólo incorporarlos a la cultura de la nación, sino ayudarlos a conformar cooperativas agrarias. En su gobierno se crearon escuelas primarias, secundarias y técnicas, al amparo de la modificación del artículo 3 constitucional, y así dar cabida a una educación socialista y laica. Hubo conflictos y oposición tanto de la Iglesia católica, como de sectores de la iniciativa privada, como de los municipios, al intento gubernamental de controlar la educación y exigir que se cumplieran los programas oficiales. En un discurso en 1937, frente a las ruinas de Monte Albán estudiadas por Alfonso Caso, Cárdenas reconoció la especificidad cultural de la etnias de México, pero al indio había que "salvarlo". Varios organismos del gobierno se encargaron de "conocer al indio". En la Universidad Nacional, fue importante el apoyo del Presidente para estudiar a los pueblos nativos del país, por parte del Instituto de Investigaciones Sociales de la Unam, desde $1939^{2}$.

El interés gubernamental por las etnias y el campo se vio reflejado en el arte: novelas que relataron la vida campesina, en el cine florecieron las películas sobre rancheros cantores y mozas con largas trenzas, los pintores recrearon esa vida y la contrastaron con la vida citadina (Quintanilla, 2010).

En el terreno intelectual, la generosidad del gobierno de México al aceptar a los refugiados republicanos e incorporarlos a la vida intelectual activa en el país, que por supuesto generó resistencia en algunos sectores, sólo daría frutos unos años después.

Estabilidad política, crecimiento económico y abandono de los ideales de la Revolución: El sexenio de Ávila Camacho (1940-1946)

Algo importante a tener en cuenta, es que al inicio de la década de los años cuarenta, México era todavía un país con una cultura rural profundamente arraigada, con lo que eso conlleva: la mentalidad campesina era cerrada, desconfiada de los cambios, resistente a la incursión de "fuereños" (Niblo, 1999, cap. 1).

1. Quizás sólo con Francisco I. Madero la cuestión de la democracia formaba parte de su programa, lo que se muestra en el lema de su campaña: "democracia efectiva, no reelección".

2. Sin embargo, en 1942, y ya con otro Presidente, Lucio Mendieta criticaba el Proyecto Paracho de educación bilingüe que Cárdenas había impulsado en Michoacán, por considerarlo comunista. 
De hecho, en 1940, de una población de más de 19 millones de habitantes, el 64.9 \% vivía en áreas rurales, e incluso los que habían empezado a migrar a las ciudades, conservaban un apego a la cultura tradicional campesina, machista, patriarcal, sobre todo en su vida cotidiana, presente incluso en los sectores más favorecidos por las circunstancias. A lo largo de la década, esta cultura mostró cambios profundos ${ }^{3}$. Los historiadores que se ocupan del periodo coinciden en señalar que las características principales del gobierno de Ávila Camacho (llamado "el Presidente caballero" por su moderación), fueron la estabilidad política, el impulso al crecimiento económico, basado sobre todo en la inversión pública y la sustitución de exportaciones, y el énfasis en la unidad de la Nación. Si bien la inclusión de todos los mexicanos era discursivamente sostenida, disminuyó notoriamente el énfasis cardenista en la importancia de campesinos e indígenas como actores del nuevo período de reformas ${ }^{4}$. Los nuevos valores de la industrialización y la modernización de México fueron el leit motiv del gobierno de Ávila Camacho, en un marco de estabilidad social y política que se consideraba fundamental para el camino escogido. Como señala Lorenzo Meyer,

Al concluir el cardenismo y estallar la segunda Guerra Mundial, la Revolución dio por terminados los grandes proyectos de reforma social y sus dirigentes decidieron y pudieron lanzar de lleno al país a una nueva empresa: la de propiciar por todos los medios el crecimiento económico; el resultado fue un notable cambio material en el país. [...] La historia de los cambios ocurridos en México a partir de 1940 es básicamente la historia del desarrollo de una base industrial moderna, aunque poco competitiva en términos mundiales y con las características propias de los países subdesarrollados: alto crecimiento demográfico, supeditación de la agricultura a las necesidades de la industria, incremento desproporcionado del sector terciario, urbanización descontrolada y una injusta concentración de la riqueza... (Meyer, 2009, p. 885).

La marginación social, tanto en el campo como en las ciudades, permaneció como un problema sin resolver, a pesar del gasto del gobierno en salud y educación.

Este periodo muestra además, el ascenso de una nueva élite al poder, conformada por políticos poderosos y empresarios importantes, cobijada por los objetivos del desarrollo estabilizador, bajo los principios de la Revolución que, sin embargo, cam-

3. Cambios que se hicieron evidentes por ejemplo en el cine: la vida urbana pasó a ser el arquetipo de una vida mejor, representada en los beneficios del confort relacionados con los aparatos domésticos. El desafío al autoritarismo paterno, el ingreso de la mujer al mercado de trabajo, fueron cambios paulatinos que se instalaron en esos años, y aunque muy lentamente, fueron modificando al menos en parte, el imaginario con respecto a lo que la vida podía ser.

4. A pesar de haber obtenido tierras y créditos con la reforma agraria, la vida de los campesinos cambió poco: la violencia no desapareció, los campesinos completaban sus magros ingresos producto del cultivo de la tierra con otros trabajos, y el acceso a los beneficios de la modernización fue reducido. 
biaron sustantivamente: de una visión cuasi socialista de la distribución de la riqueza y de los contenidos de la educación, se pasó a considerar positivamente el desarrollo del sector empresarial. Es interesante destacar, que el nuevo Presidente provenía de una familia de pequeños propietarios agrícolas, mientras que el principal líder de organizaciones obreras, Vicente Lombardo Toledano, que fue su amigo desde la niñez, era hijo de una familia que se había dedicado con éxito a la explotación de minas de cobre, si bien había perdido gran parte de su riqueza después de la Revolución. La amistad de ambos, permitió que Ávila Camacho contara con el apoyo de los líderes de la Confederación Nacional Campesina, e incluso con la del Partido Comunista, para acceder al poder, ya que en principio, el nuevo líder se comprometió a respetar el Plan Sexenal de 1940, en el que se proponían medidas redistributivas similares a las del gobierno anterior. Se acentuó el centralismo del gobierno, lo que supuso que asumiera cada vez más, tareas relacionadas con la salud de la población, la educación y la industrialización. Si con Cárdenas se dedicó el 37,6\% del gasto gubernamental para el crecimiento, esa proporción se incrementó a un 39,2\% con Ávila Camacho. Las relaciones del gobierno con poderosos grupos empresariales del norte del país, como el Grupo Monterrey, desde 1928 soporte de la Confederación Patronal de la República Mexicana (Coparmex) que aglutinaba a las principales empresas del país, en los más diversos rubros (acero, vidrio, cerveza, refrescos, cemento, etcétera), mejoraron notoriamente. La Coparmex había sido anti-gobierno en la década anterior, entre otras cosas, porque los norteños (principalmente cerveceros y de la industria del acero), habían desarrollado sus empresas sin la ayuda del gobierno, y de hecho habían apoyado a los opositores. La modificación en la política estatal con respecto al papel de la industria, significó un cambio profundo en muchos órdenes, que fue apuntalado por el hecho de que durante la Guerra, se incrementó la necesidad de productos mexicanos de exportación, mientras que la escasez de insumos otrora provenientes del exterior, favoreció la política de sustitución de importaciones.

Según señala Stephen Niblo, "la derechización" política comenzó en las filas del partido gobernante (el PRM), hacia el final de la presidencia de Cárdenas, y se concretó durante el gobierno de Ávila Camacho. Con la transformación del Partido de la Revolución Mexicana (PRM), el partido oficial, en Partido Revolucionario Institucional (PRI) en 1946, se consolidó el abandono de los ideales primigenios de la Revolución (que como dice Meyer, para esa época ya era historia): hacer de México un país donde los trabajadores tuvieran preeminencia. Sin embargo, es posible constatar una ambivalencia o duplicidad que permeó la vida de la época: discursivamente, siempre se sostuvieron los ideales del nacionalismo revolucionario y la justicia social, al punto de que aún los opositores y las clases dominantes los aceptaban como legítimos; pero en la realidad, la exigencia de la colaboración interclasista que, se 
decía, era imprescindible para el crecimiento económico y que a la vez, beneficiaría a todos, sustituyó a todo proyecto de reforma social profunda.

El impulso al sector empresarial del país, significó para muchos, la oportunidad de "hacer negocios", que si bien no eran siempre ilegales, en muchos casos no eran completamente "morales" . Si el sexenio de Ávila Camacho fue el re-inicio de la industrialización de México (que había tenido un desarrollo incipiente en el periodo de la dictadura de Porfirio Díaz), fue también el de la consolidación de prácticas corruptas.

El turismo, la industria automotriz, el petróleo y los productos agrícolas de exportación, y la obra pública (red de carreteras, obras de riego), fueron los motores del "milagro mexicano" (Meyer, 2009, pp. 886-887).

Por otro lado se vio necesaria la participación extranjera, sobre todo de los Estados Unidos, en los procesos que conducirían al desarrollo de México.

La Segunda Guerra Mundial fue para México, tanto un elemento de crisis como de oportunidad: México declaró la guerra a las potencias del Eje en 1942, y aunque su apoyo bélico fue sobre todo simbólico, el envío de minerales, productos agrícolas y braceros a los USA, contribuyó a mejorar las relaciones entre ambos países, cosa que se vio reforzada por las acciones del Departamento de Estado norteamericano, que logró que las compañías petroleras expropiadas durante el gobierno de Cárdenas aceptaran llegar a un acuerdo con México en 1943, lo que supuso una solución importante a la deuda, y la posibilidad de colocación de los productos mexicanos en mercados que se les habían cerrado por ese conflicto.

Esto condujo a una sensible mejora de las relaciones entre ambos países, que tuvo en principio como justificativo, el esfuerzo anti-fascista. Y que supuso además, el abandono de la política populista de Cárdenas, y el relegamiento de la lucha de clases.

El éxito del gobierno al consolidar un régimen de presidencia fuerte, autoritario, sin contrapesos reales, fue favorecido además por la idea de la unidad nacional, frente a enemigos externos, y coadyuvó al control por parte del gobierno, de los caudillos y caciques regionales, lo que permitió una estabilidad política que no se había conocido en las décadas anteriores.

Por otra parte, había que apuntalar el crecimiento económico con los instrumentos que la ciencia y la tecnología podían proveer. Esto implicó, por lo tanto, relaciones estrechas entre ciertos sectores de la intelectualidad mexicana con el gobierno que requería de sus servicios, e incluso, que las mismas personas fueran alternativamente, académicos y funcionarios del gobierno. Esto lo trataré en otro apartado.

5. Fue famoso el caso del hermano del Presidente de la República, el general Maximino Ávila Camacho, que fue llamado por muchos "Mr. $15 \%$ ", que era el porcentaje que exigía para apoyar cualquier emprendimiento, nacional o extranjero. Su no aclarada muerte, facilitó el ascenso al poder de Miguel Alemán, dado que el hermano incómodo tenía pretensiones sucesorias. 
La modernización autoritaria: El sexenio de Miguel Alemán (1946-1952)

Desde el cardenismo, pero sobre todo en los primeros años de la década de los años cuarenta, "se había integrado al personal político y administrativo una generación de jóvenes profesionistas que desplazó a los militares, y que prometió transformar el país mediante reformas institucionales" (Loaeza, 2010, p. 653). El peso del cardenismo y su proyecto de país disminuyó progresivamente y aunque todavía el peso de su bastión, la Confederación de trabajadores de México (стм), era grande (debemos recordar que la СтM pugnaba por el voto corporativo en la elección del candidato presidencial), desde 1946, con el ascenso del abogado Miguel Alemán (primer Presidente no militar), el modelo de desarrollo industrial acelerado y el modelo político de voto individual y democracia formal, se impuso. Cabe aclarar que si durante la Guerra democracia se asociaba con la lucha y final victoria contra los diversos totalitarismos, ya en el sexenio alemanista, el término se asociaba sobre todo al desarrollo económico y el cambio social que éste atrajo; no significó, en ninguno de los tres sexenios, elecciones realmente libres y limpias.

El periodo del presidente Alemán tuvo como caracteres distintivos el crecimiento (el gasto del gobierno destinado a fomentar el crecimiento subió a $51.9 \%$ del PIB), la modernización de México como objetivo principal ${ }^{6}$, y una corrupción desatada.

Los posibles obstáculos para implementar su gestión, fueron salvados con gran habilidad: los militares vieron disminuido su poder, entre otras cosas por conflictos internos en las fuerzas armadas, pero sobre todo, por la reestructuración implementada desde el gobierno. Los líderes sindicales fueron cooptados y cuando no, reprimidos ${ }^{7}$. La hostilidad del embajador de los Estados Unidos, que apoyaba a otro candidato, fue suprimida por el acercamiento de Alemán a la embajada, y sus posteriores encuentros con Truman, a quien convenció de su intención de mantener políticas moderadas y excluir de su gobierno a los comunistas y otros líderes de izquierda. También mejoró las relaciones con la Iglesia Católica, permitiéndole abrir centros de enseñanza.

Con el apoyo de los empresarios, la Iglesia Católica, y las clases medias en ascenso, Alemán construyó su base de poder, que le permitió gobernar en un marco de estabilidad sin precedentes.

6. En su toma de posesión Alemán afirmó: “El país entero reclama la industrialización de México”. Esto a pesar de que más de la mitad de la población vivía en el campo.

7. Lombardo Toledano, que apoyó a Alemán, a quien definió como "el cachorro de la Revolución”, fue significativamente marginado del gobierno, y si bien se arrepintió luego de haberle dado su apoyo, fue su aceptación inicial lo que facilitó el triunfo del nuevo Presidente. 
El régimen fue autoritario (nada obstaculizaba la voluntad presidencial), represor con los disidentes, y sin embargo, a decir de Soledad Loaeza, el mecenazgo estatal fomentó la creatividad artística y de innovación en las letras y el pensamiento. Según Stephen Niblo, el aliento oficial a los artistas e intelectuales, que comenzaron a vivir dentro del presupuesto estatal, fue una manera de cooptarlos y tenerlos atrapados (Niblo, 1999, cap. 4). Sin embargo, y más allá de las motivaciones del gobierno, es un hecho que la cultura y las artes florecieron en el sexenio. Durante el gobierno de Alemán se inauguraron la Ciudad Universitaria y el Instituto Nacional de Bellas Artes. El cine mexicano vivió una de sus épocas más fructíferas, la radio llegó a los hogares de la mayoría de los mexicanos y luego la televisión, aunque sólo en las clases acomodadas, fueron elementos importantísimos en la cultura de los mexicanos. Octavio Paz publicó El laberinto de la soledad en 1950. A pesar de lo cuestionable que pueda ser la imagen del mexicano que Paz postula en su obra, es una muestra de las reflexiones de los intelectuales de la época. En el terreno de la plástica, la disputa acerca de la función del arte y su estética entre los muralistas como Diego Rivera, David Alfaro Siqueiros y Clemente Orozco, que postulaban la necesidad de una pintura comprometida con los viejos ideales de la Revolución Mexicana y la lucha de clases, y los pintores como Rufino Tamayo y Carlos Mérida, que valoraban una pintura más ligada a las tendencias mundiales, nutrió el debate acerca de la identidad mexicana.

Por otra parte, la modernidad alemanista estuvo marcada por la inmensa influencia de la cultura estadounidense, los modos de vida y los nuevos artefactos del confort norteamericano, que según Daniel Cosío Villegas era "como el dios de los cristianos: todopoderosa y omnipresente" (Krauze, 2010, p. 193). El estilo de vida norteamericano, pero con escenografía mexicana, se vuelve el ideal de las clases medias (Loaeza, 2010, p. 670).

Los hijos (des) ilusionados de la Revolución

Más allá del cuestionamiento que se le puede hacer al concepto de "generación", por lo que puede implicar de supuesta homogeneidad o similitud de orígenes y trayectorias, que no siempre se corresponden con la realidad, lo cierto es que la llamada "Generación del 15", tuvo un papel protagónico en el escenario intelectual

8. Miembros de la llamada por Gómez Morin “Generación del 15” son, además del propio G. Morin, Alfonso Caso, Vicente Lombardo Toledano, Antonio Castro Leal, Jesús Moreno Baca, Teófilo Olea y Leyva y Alberto Vázquez del Mercado, conocidos como "Los siete sabios de México", que no eran viejos ni eran tan sabios. A ellos se suman posteriormente Narciso Bassols, Luis Enrique Erro, Juvencio Ibarra, Miguel Palacios Macedo, Manuel Toussaint y Daniel Cosío Villegas, que eran entre dos y cuatro años más jóvenes que los anteriores. 
inmediatamente después de la Revolución, e incluso muchos de sus miembros continuaron ejerciendo diversas funciones dentro o ligadas con los sucesivos gobiernos revolucionarios a lo largo de varias décadas. Si algo se impone, es considerar cómo muchos de ellos, al ver truncadas sus aspiraciones políticas, se inclinaron por el desarrollo de una actividad intelectual, académica o dentro de instituciones que crearon o ayudaron a consolidar.

¿Cuál es el ambiente en el que desarrollan sus vidas? Hay que tener en cuenta, que los sucesivos gobiernos del país, de 1915 a 1940, estuvieron comandados por militares, algunos de ellos jóvenes, incultos, que no tenían un equipo ni asesores confiables en el terreno de las políticas públicas.

Los jóvenes ilustrados que fundaron el Ateneo de la Juventud ${ }^{9}$ en 1909, habían intentado introducir de nueva cuenta los valores del conocimiento y las humanidades (que durante el gobierno larguísimo de Porfirio Díaz habían sido relativamente menospreciados en aras de una visión utilitaria-positivista), en los cursos que impartieron mientras aún se desarrollaba la contienda. Algunos se unieron a la Revolución, tanto en el bando triunfante como en el de los perdedores ${ }^{10}$. Vasconcelos por ejemplo, que fue miembro del gabinete de noviembre de 1914 a enero de 1915, inició el primero de sus exilios en 1915 por oponerse a Carranza, y regresó al país en 1920. Sólo Antonio Caso, que tenía 33 años en 1915, se quedó en la capital e impartió clases de diversos temas, donde pudo.

Sus alumnos, los hombres del 15, que a la sazón tenían de 17 a 20 años, sintieron que su papel no debía reducirse sólo al ámbito cultural, creían que debían hacer algo por México, y se involucraron estudiando problemas económicos y sociales que consideraban acuciantes, sobre todo, los del campo. Es importante señalar, entonces, que hubo diferencias y similitudes entre los miembros del Ateneo y los de la llamada Generación del 15: por una parte, el interés por la cultura y las humanidades permearon la concepción que de su propia labor tenían los ateneístas, a diferencia de los del 15, que consideraban necesario realizar estudios que pudieran ser útiles para resolver los problemas de la sociedad naciente. Las similitudes están en que ambos grupos consideraron la actividad académica y la labor política como inseparables, aunque el grado de involucramiento en una u otra varió notablemente según la per-

9. José Vasconcelos, Alfonso Reyes, Pedro Henríquez Ureña, Antonio Caso, Julio Torri, Martín Luis Guzmán.

10. El caso del padre de Alfonso Reyes, el general Bernardo Reyes, que siendo porfirista condujo a toda la familia al exilio, del cual su hijo, afamado escritor, sólo regresó décadas después, para hacerse cargo de la dirección de la Casa de España en México. O el de Vasconcelos, y el dominicano Pedro Henríquez Ureña, que no le apostaron al general Carranza, que triunfó sobre los demás, y eso los condujo temporalmente al exilio. 
sonalidad y los intereses de cada quien, los llamados desde el gobierno que fueron diferentes en cada circunstancia, las afinidades políticas en los distintos momentos.

El clima intelectual, sobre todo después de 1920, era de exaltación patriótica, y toma de conciencia de lo propiamente mexicano; los artistas pintaron, escribieron y musicalizaron temas populares, y la plana mayor de la joven generación de universitarios fue convocada y promovida en diversos puestos importantes del gobierno. Manuel Gómez Morin fue Subsecretario de Hacienda a los 23 años, Alberto Vázquez del Mercado fue Secretario de Gobierno de la capital a los 27. Los que aún estudiaban leyes ingresaron al servicio público a través de la Universidad y de la Secretaría de Educación Pública, sobre todo cuando José Vasconcelos fue nombrado primero Rector de la Universidad Nacional y luego Secretario de Educación. En esos cargos, Vasconcelos promovió una cruzada alfabetizadora, de creación de bibliotecas, becas, ediciones gratuitas y demás, que convocó tanto a sus antiguos compañeros ateneístas $^{11}$, como a los jóvenes miembros de la Generación del 15. El retorno al país de Henríquez Ureña, hizo que varios de sus alumnos asumieran la honestidad intelectual, el rigor y el respeto por la vida académica y la cultura, como valores a defender el resto de sus vidas, aún desde diferentes posiciones, y a pensarse a sí mismos como los verdaderos herederos de la Revolución, no porque la hubieran hecho, sino porque asumían sus ideales y objetivos (Krauze, 2015, p. 65). Durante las décadas de los 20 's y 30 's, las trayectorias de cada uno se hicieron divergentes, algunos se entregaron al trabajo político, como Lombardo, y otros como Gómez Morin, a sus carreras como abogados y funcionarios, pero todos conservaron sus lazos con los gobiernos en turno, porque vivir completamente fuera del presupuesto estatal era perder la oportunidad de incidir en el derrotero del país. Eso no impidió que algunos, como Daniel Cosío Villegas, que se vio beneficiado con becas, subvenciones gubernamentales y cargos diplomáticos, comenzaran a cuestionar el rumbo que iba tomando el país, y ciertos mitos de origen que impedían conocer las limitaciones y los desafíos que se enfrentaban. Entre esos mitos, estaba el de que México era un país rico, algo así como "el cuerno de la abundancia". Este mito impulsado inicialmente desde la colonización por Bernal Díaz del Castillo y luego por Humboldt, ocultaba las tremendas carencias materiales del país que los hijos de la Revolución tenían que afrontar e intentar resolver. E incluso, Cosío cuestionaba las interpretaciones sobre los males mexicanos que otros miembros de la generación publicaban, porque decía que no estaban basados en estudios serios, científicos, de la realidad nacional. Hacía falta estudiar a México. Varios de sus compañeros de la Escuela de Jurisprudencia

11. Julio Torri, luego Carlos Pellicer, fueron los directores de Bibliotecas Populares y Ambulantes, uno de los proyectos de Vasconcelos. Torres Bodet, a la sazón de 20 años, asumió la Dirección de 1922 a 1924. 
fueron, como él mismo, a estudiar economía a otros países, y luego, a su regreso, fueron llamados a ocupar plazas en el gobierno ${ }^{12}$.

En la década de los años 30's, varios miembros de la Generación del 15 entraron en una crisis personal: no habían robado, eran honestos, aún alentaba en ellos el ideal de contribuir a la transformación del país, pero no tenían una obra, no una de real importancia ${ }^{13}$. Gómez Morin y Vasconcelos decidieron separarse de los gobiernos de la Revolución con la convicción de que nada podía prosperar en ese tejido de corrupción y violencia, pero tenían al menos la satisfacción de haber iniciado una obra que seguía en pie: Gómez Morin el Banco de Crédito Agrícola y Vasconcelos las profundas reformas educativas (Krauze, 2015, p. 93). A los 35 años, Villaseñor y también Cosío, sentían que la Generación había fracasado en sus anhelos de cambio. Sin embargo, es el momento en que comienzan a reorientar sus proyectos. El caso de Cosío es paradigmático: convencido de la necesidad de que los economistas mexicanos accedieran a la bibliografía clásica y a los debates internacionales en la materia, consiguió financiamiento de diversas fuentes: el gobierno, amigos funcionarios, empresas, fundaciones extranjeras, y fundó una revista, El Trimestre Económico y una editorial, el Fondo de Cultura Económica (FCE) ${ }^{14}$ en 1934. Si bien sus aspiraciones de ser Secretario de Relaciones Exteriores de México se vieron truncadas, esto hizo que se dedicara a hacer estudios que el gobierno le encargó, y a una cada vez más intensa labor editorial.

El período de gobierno del general Lázaro Cárdenas se caracterizó por el impulso a grandes reformas sociales, sobre todo referidas a la situación de los campesinos. Algo en lo que la mayoría de los autores están de acuerdo, es en que fue el último gobierno en el que se sostuvieron los objetivos originales de la Revolución. Su política educativa y cultural ${ }^{15}$ constituyó un momento de auge para muchos de los intelectuales mexicanos: varios de los miembros de la Generación del 15 obtuvieron buenos puestos gubernamentales y de poder. Gómez Morin, por ejemplo, fue Rector de la Universidad Nacional en 1933, pero salvo en ese momento, siempre ejerció de abogado en su bufete.

12. Cosío fue a Harvard, a la Universidad de Wisconsin y luego a Cornell; Espinosa de los Monteros a Harvard, Palacios Macedo a París; también viajaron como funcionarios y para aprender, Gómez Morin y Eduardo Villaseñor, amigo íntimo de Cosío.

13. Cartas de Eduardo Villaseñor a Cosío Villegas (Krauze, 2015, p. 92).

14. Miembros de la primera Junta de Gobierno del fCE: Gómez Morin, Adolfo Prieto (empresario de la importante Fundidora Monterrey), Eduardo Villaseñor, Emigdio Martínez Adame (de la Secretaría de Hacienda), Gonzalo Robles (del Banco Hipotecario), Jesús Silva Herzog y Daniel Cosío Villegas.

15. Cárdenas desconfiaba sin embargo de los intelectuales, y Cosío decía del Presidente que era pueblerino, poco culto. Su gobierno fue quizás desordenado, pero pletórico de impulsos generosos (Krauze, 2015, p. 107). 
La década de los 40's fue de consolidación de esos emprendimientos culturales: Vasconcelos, de regreso de su tercer exilio ${ }^{16}$, fue nombrado Director de la Biblioteca Nacional (un cargo menor, pero dentro del presupuesto). Su íntimo amigo y compañero del Ateneo (vid. Garciadiego, 2015, pp. 160 y ss.), Alfonso Reyes, que había sido convocado por el gobierno de Cárdenas, realizó una admirable labor en la Casa de España, luego Colegio de México, y continuó escribiendo y publicando; Gómez Morin, desencantado frente a la política oficial, fundó en 1939 el Partido Acción Nacional. 1938 fue un año de crisis en México por varios motivos, como ya se señaló más arriba, sobre todo por las repercusiones de la expropiación petrolera impulsada por Cárdenas. Y también fue un año de crisis en el plano personal para uno de los personajes más importantes de la historia intelectual de este país, Cosío Villegas, que viendo frustradas sus aspiraciones políticas, se dedicó, para bien de muchos y de él mismo finalmente, a proyectos de empresa cultural; entre otros, propuso y promovió la labor de los refugiados españoles como traductores, maestros y pensadores. Otro ejemplo es su gestión al frente del Fondo de Cultura Económica, que permitió consolidar un proyecto de gran envergadura editorial, que había iniciado Vasconcelos, pero que se consolidó con bajo su impulso: la independencia de la industria cultural mexicana con respecto a las editoriales españolas.

Los transterrados españoles, El Colegio de México y la labor editorial

La Guerra Civil española (1936-1939) fue un hito importantísimo para la cultura en México: Cosío Villegas se dio cuenta de que esa situación crítica hacía necesaria una propuesta del gobierno mexicano que permitiera recuperar a los intelectuales perseguidos e inició la llamada "Operación inteligencia”, que permitió traer al país a un número creciente de profesores e investigadores en diversas disciplinas. Uno puede considerar el acto como uno de extrema solidaridad y generosidad ante la crisis de la madre patria por parte de México, pero también como la oportunidad de integrar al débil panorama cultural mexicano, la experiencia y los conocimientos de los españoles, que después de 40 años de bonanza, se habían constituido en una fuerza importante de la cultura en Europa. Alfonso Reyes, ateneísta 10 años mayor que Cosío; un hombre amable, escritor con fama propia, que radicó en el exterior por muchos años y conocía bien a muchos pensadores que se intentaba atraer y apoyar en México, a la sazón en un puesto diplomático que se veía amenazado por los

16. El primero fue, como se señaló más arriba, de 1915 a 1920; el segundo, de 1925 a 1928, ocasionado por su derrota en su pretensión de ser elegido gobernador de su natal Oaxaca; el tercero, fue de 1929 a 1938, ocasionado por la victoria de su opositor Pascual Ortiz Rubio en la elección presidencial de 1929. 
recortes presupuestales, fue encargado por Cárdenas de presidir La Casa de España en $\mathrm{México}^{17}$ en 1938.

Cuando los republicanos perdieron la Guerra Civil en España, gracias a la política de Cárdenas que aceptó darles asilo, comenzaron a llegar a México muchos refugiados, entre los que se encontraban médicos, profesionistas, maestros. El proyecto que Cosío impulsó, apoyado por el gobierno de Cárdenas, era constituir a La Casa en una institución no sólo de acogida, sino de cultura superior, un centro de investigación, a través del cual se desarrollaran actividades que se consideraban importantísimas para la cultura mexicana: enseñanza en diversas instituciones, como la Unam y varias universidades de provincia, pero sobre todo, traducciones de textos clásicos y de los materiales producidos en el extranjero y por lo tanto de difícil acceso en el país, de las disciplinas que comenzaban sus procesos de institucionalización y profesionalización en México. Krauze señala que "la inventiva cultural de Cosío Villegas inició un pequeño milagro: convertir un exilio en una empresa, un destierro en un floreciente transtierro" (Krauze, 2015, p. 120); convertir una crisis externa, en una oportunidad para el país. La mayoría de los transterrados españoles comenzaron a colaborar con el FCE; varios también, sobre todo aquellos que podían iniciar un ejercicio profesional independiente, como los abogados y los médicos, gracias a las gestiones de varios intelectuales mexicanos, se integraron a la Universidad Nacional.

En 1940 La Casa de España se transformó en El Colegio de México (Colmex). El financiamiento de la nueva institución estuvo a cargo del Banco de México, la SEP, la Unam y el FCE. Sin embargo, la penuria en cuanto a los fondos, fue una constante en esos primeros años. Los estrechos contactos que desde un principio estableció El Colegio de México con la Universidad de Harvard, eran una muestra del nivel de excelencia que se buscaba. Pero en 1942, ya con Ávila Camacho en el gobierno, el financiamiento se hizo casi imposible; la Universidad ya no podía colaborar con el mantenimiento (nunca fue muy importante el monto con el que contribuyó, de todas maneras), el FCE tenía sus propios problemas, y el Banco de México hizo su última aportación en 1944. Cosío Villegas buscó entonces otras fuentes de financiamiento y recurrió a la Fundación Rockefeller, que ya había apoyado varios estudios en México, y al propio Cosío cuando estuvo en los Estados Unidos. A pesar de las dudas que tal apoyo ha generado en investigadores en México, sobre todo porque es un apoyo que resultó crucial en la historia posterior del Colegio, en cuanto al otorgamiento de becas (entre otros, al propio Cosío Villegas al final de la década de los 40's y

17. Los miembros del Patronato de La Casa de España fueron Alfonso Reyes, Eduardo Villaseñor, el director del Politécnico Nacional, Gustavo Baz (Rector de la Universidad Nacional), y Daniel Cosío Villegas. 
parte de la de los años 50, lo que le permitió iniciar su ambicioso proyecto sobre la Historia de México); y la creación de centros de investigación del Colegio y las líneas de investigación promovidas en esos centros; creo que es posible entender que en el momento de la creación de instituciones, y en los procesos de consolidación de empresas culturales ambiciosas, quizás el fin justifica los medios, y el pragmatismo se impone ${ }^{18}$. Es cierto que al momento de aceptar financiamiento de Fundaciones norteamericanas, éstas intentan controlar de alguna manera a dónde van y cómo se ejercen sus fondos, lo cual es de esperarse, pero creo que la habilidad de Cosío, al menos en esos primeros momentos de El Colegio de México, fue jalar los apoyos hacia donde más le convenía, reteniendo para la institución el control último de los proyectos. Las clases se impartían en forma de seminarios, el ambiente en general era riguroso y esto coadyuvó a que en El Colegio se formara la élite intelectual que México necesitaba y que incidió posteriormente de manera amplia y destacada en las instituciones y la cultura del país. Entre 1941 y 1951, pasaron por sus aulas Pablo González Casanova (futuro Rector de la Universidad Nacional y destacadísimo y comprometido intelectual a lo largo de su vida), y Luis González, importante historiador y formador de historiadores, entre muchos otros. Aunque el Centro de Estudios Sociológicos comandado por José Medina Echevarría, en su primera etapa tuvo corta vida, dejó la semilla para el desarrollo de la sociología de manera formal y académicamente consistente. Raimundo Lida, otro transterrado, dirigió el Centro de Estudios Lingüísticos desde 1947 y atrajo desde Argentina, donde la situación política no era favorable, la Revista de Filología Hispánica, que se publicó a partir de entonces en México; el mexicano Silvio Zavala dirigió a partir de 1946, el Centro de Estudios Históricos. Bajo la dirección de Alfonso Reyes (el bueno) y Daniel Cosío Villegas como secretario y administrador (el malo, encargado de suspender becas, despedir gente, y rendir cuentas), el Colegio floreció, a pesar de que atravesaba serias penurias económicas: los salarios de los profesores eran bajos, comparados con los de otras instituciones, y las becas también. A fines del 46 Cosío se apartó del Colmex para dedicarse al FCE, y en 1948, gracias a una beca de F. Rockefeller, pudo dar inicio a su proyecto sobre la Historia Moderna de México.

Como una muestra ${ }^{19}$ de las relaciones entre personas y grupos, y de la profunda, útil y a veces conflictiva y frustrante imbricación de las elites intelectuales con los gobiernos en turno, propongo abordar tres empresas culturales de gran importancia

18. O como decía Deng Xiaoping, refiriéndose a los capitales necesarios para desarrollar económicamente a China después del estrepitoso fracaso de la Banda de los Cuatro al final de la Revolución Cultural de Mao Zedong, "no me importa el color del gato, con tal de que sepa cazar ratones".

19. Y nada más que eso, porque emprendimientos culturales en el terreno de la educación, las ciencias y las artes hubo muchos en el periodo objeto de estudio de este trabajo. 
para México y sus incipientes comunidades científicas en el terreno de las ciencias sociales: El Fondo de Cultura Económica, la revista Cuadernos Americanos, y la Revista Mexicana de Sociología ${ }^{20}$.

\section{El Fondo de Cultura Económica}

Como bien dice Enrique Krauze: "La historia de la cultura en un país no es sólo la de sus autores y sus obras. Es también la historia material de esa cultura. Dentro de ella, uno de los capítulos fundamentales es el de la industria editorial" (Krauze, 2015, p. 135). La dependencia de México de la producción de libros en Francia y España, sólo se modificó con el impulso educador de Vasconcelos primero, efímero sin embargo, y con la obra de construcción editorial de Cosío Villegas después. Cosío comprendió la necesidad de romper con la hegemonía y el poderío franco español en materia editorial, y además consideró vital para la formación de los universitarios mexicanos, el que pudieran tener acceso a la literatura especializada, en castellano. En 1934 creó el Fondo de Cultura Económica, que para el final de la década, contaba con el trabajo de los inmigrantes españoles para la selección y traducción de las obras ${ }^{21}$.

No más de diez personas se encargaron en un principio de gestionar el FCE, haciendo las traducciones, encargándoselas a especialistas, seleccionando las obras a ser traducidas, diseñando los libros, editándolos y haciendo la corrección de estilo. En 1940 se puso en marcha la imprenta propia, la Gráfica Panamericana. Sin el arduo trabajo de los intelectuales españoles, y sus esposas, que hicieron muchas de las traducciones, el crecimiento y la expansión del FCE, que pretendió llegar a toda Iberoamérica, hubiera sido imposible.

Españoles fueron también los directores de diversas colecciones y secciones de la producción editorial del Fondo, que no sólo estaban dedicadas a la economía, sino a la historia, la sociología, la política y el derecho, la antropología, la filosofía y la música ${ }^{22}$.

20. La elección de estos tres emprendimientos culturales no es arbitraria: los tres continúan hasta el día de hoy aportando a la cultura de México.

21. En el trabajo de traducción, fue importantísima la labor de las mujeres transterradas: esposas de los intelectuales migrantes, muchas de ellas con producción propia, como fue el caso de Ernestina de Champourcin Moran de Toledo, esposa de Juan José Domenchina, que fuera secretario de Manuel Azaña en la República Española. Poetisa por derecho propio, tradujo más de 15 libros para el FCE; perteneció a la "Generación del 27” en España, y después de la muerte de su esposo publicó varios libros impregnados de religiosidad y simbolismo.

22. José Medina Echevarría, Sociología (colección que siguió dirigiendo durante varios años, aún después de haber abandonado México); Javier Márquez, Economía; Wenceslao Roces y Ramón Iglesia, Historia; Manuel Pedroso y Vicente Herrero, Política y Derecho; Juan Comas, Antropología; José Gaos, Filosofía; Adolfo Salazar, Música. 
Repasando los títulos y autores de los libros publicados por el Fondo desde 1934 a 1950, se puede observar lo que fue el objetivo principal en esa época: hacer accesible a un público necesitado de conocimientos, tanto textos clásicos como recientes en diferentes disciplinas. Si bien predominaron, de 1934 a 1950, los libros de economía (109), también son notorios los cruciales textos publicados para sociología (45), política y derecho (49), historia (51) y antropología (30). La mayoría de los autores fueron europeos: Sombart, Malthus, Stuart Mill, Marx, Marshall, Keynes; los dos Weber, Mannheim, Tönnies, Comte, y biografías de los fundadores de la sociología; Locke, Hobbes; Boas; Ranke, Pirenne, Burckhardt. Eso para mencionar sólo algunos.

En cantidad reducida, pero en la línea que se había propuesto Cosío, también figuran obras de autores mexicanos, españoles y latinoamericanos ${ }^{23}$. En 1948, Cosío dejó la dirección del FCE, que pasó a manos de Arnaldo Orfila, un colega de su confianza que dirigía hasta ese momento la filial de Buenos Aires. También es muy destacada la labor de Orfila, que impulsó una línea editorial novedosa y pujante.

Otras colecciones promovidas por el FCE tuvieron destinos disparejos: la colección Breviarios, para poner al público en general en contacto con importantes desarrollos del conocimiento en formato accesible; la Biblioteca Americana, un proyecto de Cosío y Henríquez Ureña que se vio en cierta medida frustrado por la temprana muerte de Henríquez en Buenos Aires, y que no tuvo el éxito esperado entre los autores latinoamericanos que respondieron sin demasiada pujanza a sus convocatorias; Tezontle (de literatura y ensayos) y Tierra Firme.

\section{Cuadernos Americanos}

México fue el país que más refugiados españoles recibió: cerca de 18.000. Muchos de ellos, intelectuales formados en lo que se consideró la "Edad de plata" de la cultura ibérica, cuando muchos fueron a estudiar a otros países de Europa (Alemania, Italia) y a los Estados Unidos, y en España existían instituciones como el Instituto Libre de Segunda Enseñanza. La idea de publicar una gran revista, ya en territorio mexicano, se fraguó en París, con el apoyo de varios diplomáticos mexicanos, incluido el embajador,

23. Emilio Barreto, Armando Servín, Ernesto Galarza, Ernesto Lobato López y Luis Roque Gondra, la mayoría de cuyos trabajos trataban de aspectos acotados pero importantes para el desarrollo del pensamiento económico mexicano. Del mismo Cosío y de Oscar Morineau en la colección de política y derecho; de José Medina Echavarría y Luis Recaséns para sociología; de Andrés Bello, Rubén Darío, Gonzalo Aguirre Beltrán, Lucio V. Mansilla, Silvio Zavala y María Castelo para antropología; José Valadés, Luis Castillo Ledón y Silvio Zavala para historia. 
Narciso Bassols ${ }^{24}$. Primero fue "España peregrina” que duró poco tiempo, y luego, con el apoyo de Alfonso Reyes (a él se le debe el nombre); la presidencia de Jesús Silva Herzog, a la sazón encargado de los Estudios Económicos de la Secretaria de Hacienda mexicana, y el español Juan Larrea como secretario, inició la publicación de Cuadernos Americanos en 1942. En la presentación del primer número, en una cena a fines de 1941, Reyes señalaba que la revista respondía a "un imperativo moral [...], [constituía un] esfuerzo por la salvación de la cultura, es decir, la salvación del hombre” (Tierno, 2010).

La Junta de Gobierno estaba integrada por 6 mexicanos y 5 españoles, y en sus páginas es evidente la amplia participación de la intelectualidad mexicana junto con la de los emigrados, para los que Cuadernos Americanos significó su integración a la tierra de acogida. En palabras de Ana González Neira "el exilio cultural español se vio obligado a asumir que no podía continuar viviendo en la aislada burbuja de la diáspora”. Su integración era obligada: la derrota iba a durar mucho tiempo (González Neira, 2009, p. 15).

La labor de Larrea fue inmensa, desde la idea de la portada, con unas "ondas en movimiento" que simbolizaban el mar, con sus múltiples significados, hasta la elección de las ilustraciones, la edición e incluso los asuntos administrativos y secretariales $^{25}$, cosas todas que se realizaban con gran austeridad y escasez de recursos ${ }^{26}$. Para garantizar la independencia en la línea editorial de la revista, Silva Herzog prefirió buscar muchas donaciones pequeñas, aparte de la del fisco y empresarios amigos. Así, es posible ver en sus páginas de inicio, anuncios de cervezas, cigarrillos, imprentas, editoriales, empresas de crédito, refresqueras, industriales azucareros, y Pemex, la petrolera estatal recientemente nacionalizada, todos convocados para hacer su aporte a la cultura de México ${ }^{27}$.

La revista tenía 4 secciones: Nuestro Tiempo (ensayos sobre asuntos de actualidad, e internacionales); Aventura del Pensamiento (materias filosóficas y científicas); Presencia del Pasado (historia, arqueología y antropología); Dimensión Imaginaria (creación y estudios de arte y literatura). Más una serie de ilustraciones y fotografías.

Varias cuestiones son dignas de mención: la primera, es la colaboración de al menos 88 españoles en los números de la revista entre 1942 y 1949, todos ellos, des-

24. El diplomático mexicano Gilberto Bosques, a punta de pistola, salvó en Marsella a Manuel Azaña de ser aprehendido por fuerzas fascistas; lamentablemente, Azaña, con su salud debilitada, murió en las oficinas improvisadas de la Legación mexicana en esa ciudad, sin poder viajar a México.

25. El mismo Larrea señala sus múltiples tareas en dos cartas dirigidas A Silva Herzog, después de dejar la revista.

26. Hay que tomar en cuenta que Cuadernos Americanos se publicaba cada 2 meses, lo que implica un esfuerzo editorial considerable.

27. El estudio de la iconografía publicitaria de la época en Cuadernos Americanos, es una tarea aún pendiente, pero relevante, para la sociología de la cultura. 
tacados intelectuales en diversas ramas del saber, que llegados a México en algunos casos hubieron de modificar sus áreas de estudio, o sus enfoques, para adaptarse a las necesidades de su tierra de adopción y “comenzar de nuevo”, y que publicaron un número apreciable de textos ${ }^{28}$. En el mismo período publicaron en la revista mexicanos destacados, como Alfonso Caso, Daniel Cosío Villegas, Rodolfo Usigli, Leopoldo Zea, Eduardo O'Gorman, Samuel Ramos, Silvio Zavala, Andrés Henestrosa y otros.

La segunda cuestión, se refiere a los contenidos: en Cuadernos Americanos se plasmaron en forma de ensayos y artículos algunos de los intereses que surgieron con fuerza en el horizonte cultural de la época: el indigenismo, el rescate de las huellas del pasado pre-hispánico, y sobre todo, la visión de América como tierra de promisión. Y al hacerlo, iniciaron una serie de debates sobre la identidad, la cultura, el presente y el futuro, y el papel de la historia. Muestra de ello es el debate entre Juan Larrea, que, como otros de los exiliados, tenía una visión utópica y sublimada de América, una tierra donde surgiría, tras el desastre y la decadencia en Europa, una sociedad nueva; y el mexicano José Iturriaga, más realista, que no comparte la idealización de América y acusa a Larrea de proponer un "mito geográfico", que desconoce la realidad del continente ${ }^{29}$ (Véase González Neira, 2009).

También fue un espacio para la reflexión y la crítica acerca del camino que en México tomaba la revolución institucionalizada: ejemplo de esto, es que Cosío Villegas publica en las páginas de la revista, en 1947, un artículo sumamente crítico con los gobiernos de la Revolución, donde dice que México vive desde hace ya bastantes años una crisis, cuyas causas son la pérdida de vigencia de los ideales y metas revolucionarias (libertad política, reforma agraria y organización obrera, disminución de la desigualdad), que si bien en parte se lograron, han venido acompañadas de gobiernos mediocres, malos administradores y una corrupción generalizada, en un marco de inseguridad creciente ${ }^{30}$.

Y que provocó una serie de respuestas y debates que reafirmaron en Cosío la voluntad de estudiar concienzudamente la historia de México y que lo llevó, entre otras cosas, a iniciar desde 1948 su gran proyecto de la Historia Moderna de México, que se convertiría en una obra principal e imprescindible ${ }^{31}$.

28. José Gaos, 28 artículos; Juan Larrea, 21; Eugenio Ímaz, 19; Medina Echavarría,11; León Felipe, 10; Francisco Giner de los Ríos, 9; Joaquín Xirau, 9.

29. "Larrea afirma que uno de los indicios que señalan a América como tierra elegida es la unidad del lenguaje, sin tener en cuenta que por ejemplo, en el México de la época se hablaban alrededor de 65 lenguas indígenas" (Tierno, 2010, p. 5).

30. “Todos los hombres de la Revolución... han resultado inferiores a las exigencias de ella” (Cosío Villegas, 1947, pp. 29-51). El texto resulta de una actualidad apabullante...

31. Cabe aclarar que Cuadernos Americanos, a cargo de la Unam, continúa publicándose hasta el día de hoy. 


\section{La Revista Mexicana de Sociología}

La Revista Mexicana de Sociología (RMS) surgió como parte de un proyecto mayor: generar investigaciones que ayudaran a esclarecer la composición de la sociedad mexicana, sus problemas más acuciantes y las maneras de resolverlos. Si bien por la formación y los intereses de los miembros del Instituto de Investigaciones Sociales que se involucraron con ella al principio, estos objetivos sólo se cumplieron parcialmente, puede decirse que las aportaciones realizadas fueron sin embargo, en varios casos, de gran importancia. Es curioso cómo la sociología comenzó su proceso de institucionalización en México, de la mano de abogados, antropólogos y médicos ${ }^{32}$. Esto obviamente sesgó el contenido de las primeras publicaciones, pero además, el estilo de muchos de los artículos publicados tiene un tufillo discursivo, retórico, prejuicioso, que ahora, muchos años después, difícilmente podríamos calificar como científico.

Lo que es importante señalar, es que si bien su director, Lucio Mendieta y Núñez, que al mismo tiempo fungía como director del Instituto de Investigaciones Sociales de la Universidad Nacional Autónoma de México (Unam), fue funcionario de los sucesivos gobiernos de la época, primero como especialista en derecho agrario y luego en varios puestos relacionados con investigaciones sociales y en asuntos indígenas, y también del PRI, los trabajos emprendidos tanto en el Instituto como en la Revista, si bien respondían a necesidades acuciantes vistas como tales por diversos sectores, incluidos los sucesivos gobiernos, e incluso apoyados por éstos, no eran por encargo manifiesto, ni tenían destinatario específico, como sí lo tuvieron otras revistas como El Trimestre Económico, fundada por Cosío Villegas casi al mismo tiempo que el FCE. El propósito, como el mismo Mendieta se ocupó de remarcar una y otra vez, era aportar conocimiento concreto, empíricamente obtenido a través de estudios de campo, de la realidad del país, que pudiera ser utilizado tanto por los interesados en temas sociales como por las autoridades, para así sustentar científicamente las políticas de desarrollo que México tanto necesitaba. Si bien Mendieta (1895-1988) perteneció, por fecha de nacimiento y trayectoria intelectual, a la Generación del 15, no pareciera haber formado parte del mismo grupo que Cosío, Villaseñor, Gómez Morin y Lombardo. Sus contactos se gestaron principalmente en la ENJ, y luego en el gobierno, con Manuel Gamio como mentor, y su acción estuvo marcada principalmente por su relación con el ámbito jurídico. Tres cuestiones son destacables en cuanto al contenido de la revista: por una parte, el énfasis puesto en la necesidad de realizar una descripción y cuantificación de la presencia indígena en México. Se

32. Abogados, antropólogos, médicos y criminalistas fueron los de mayor presencia en los primeros años de la revista: Alfonso Quiróz Cuarón, Manuel Gamio, Rafael Heliodoro Valle, entre otros. 
publicaron monografías sobre cada etnia, en las que se trató de proporcionar una visión abarcadora de la situación de los indios: su apariencia física, su carácter, su hábitat, sus vicios, sus costumbres (vid. Olvera, 2004, pp. 98 y ss.). Si bien la Carta Etnográfica de la República Mexicana no logró salir a la luz en 1947 por falta de fondos, luego se publicó el Atlas Etnográfico, y las diversas monografías sobre las etnias de México se publicaron en un libro en 1957, pero ese material "desapareció" (vid. Warman, 1989, p. 138, apud Olvera, 2013, p. 238, nota 302). En las descripciones proporcionadas, predominaban los prejuicios raciales y políticos de la época, con el objetivo de la unidad nacional: las culturas indígenas debían integrarse borrando sus características propias ya que en caso contrario serían un obstáculo al desarrollo del país; la visión de los indígenas como pasivos, impenetrables, alcoholizados, imposibles de "redimir". Los autores de la RMS sostienen que uno de los problemas más graves de México es su heterogeneidad cultural, que sólo puede eliminarse a través de la educación de los niños nativos: los adultos ya están perdidos.

Por otra parte, la concepción que Mendieta ${ }^{33}$ tenía de la sociología era que debía ser una ciencia empírica, con una utilidad práctica evidente, si bien debía basarse teóricamente en las grandes obras de sociólogos europeos, que él se propuso dar a conocer en las páginas de la publicación. Tradujo textos de Durkheim, Holbwachs y Raymond Aron, muchos de ellos originales y no publicados en otras lenguas, conseguidos a partir de sus contactos y en algunos casos, incluso de su amistad personal con varios de ellos ${ }^{34}$. Al mismo tiempo promovió la publicación de textos sobre metodología y técnicas de investigación estadounidenses que debían abonar los estudios empíricos en México. Y dio cabida, aunque probablemente con un cierto disgusto, a intelectuales españoles transterrados, de formación filosófico-humanista, como Recaséns o más sistemáticos en sus conocimientos sociológicos, como Medina.

En la revista no hubo debate entre las distintas posiciones, tan sólo veladamente, por parte de los más temperamentales ${ }^{35}$.

Y por último, a diferencia de Cuadernos Americanos, la $R M S$ prácticamente no trató, salvo en algunas pocas colaboraciones de autores extranjeros, el problema de la Guerra Mundial y sus consecuencias. Salvo por el interés en formulaciones teó-

33. Medina ejerció un liderazgo unipersonal y hasta cierto punto autoritario tanto en la revista como en el Instituto. Fue el suyo un liderazgo organizacional más que intelectual, porque no generó escuela; fue un caudillo institucional, en varios de los sentidos del término: por su relación con el Partido de la Revolución Institucionalizada (el PRI), y por ser generador de instituciones (el IISUNAM) y promover la institucionalización temprana de la disciplina sociológica.

34. Entre los autores extranjeros publicados en la RMS en esa primera década, encontramos a Malinowski, Harry Alpert, Howard Becker, Stuart Chapin, Thomas French, Pauline Young, entre otros.

35. Es el caso de Recaséns Siches y sus comentarios sibilinos a las posiciones durkheimianas de Mendieta y Núñez. También Silva Herzog se refirió al carácter poco amable de Recaséns. 
ricas de reconocido valor, a las que la revista dio oportunidad de darse a conocer, cuando la situación en Europa les dificultaba su publicación o difusión en origen, y la incorporación de reflexiones provenientes de otros países de América Latina, la mirada de la $R M S$ en esos años fue hacia el interior de la sociedad mexicana.

Reflexiones finales

Ni los miembros del Ateneo ni los de la Generación del 15 conformaron una comunidad científica, pero dieron origen a muchas. Mejor dicho, incidieron profundamente en el horizonte cultural, científico y de políticas públicas en México, y con ello sentaron las bases institucionales para el desarrollo de diversas disciplinas, empresas editoriales, y emprendimientos científicos de largo alcance.

La legitimación del poder simbólico de los intelectuales vino dada en México por varias vías: la construcción de instituciones (carreras universitarias como la de Economía, el FCE, El Colmex y el Instituto de Investigaciones Sociales de la Unam); la participación en puestos políticos relacionados con cuestiones educativas, culturales y ligadas al desarrollo económico y la modernización del país (Eduardo Villaseñor, Gómez Morin y otros, en el Banco de Crédito Agrícola, por ejemplo) en los que fueron nombrados por los diferentes gobiernos; su propia producción científico-cultural (escritores como Alfonso Reyes; historiadores y ensayistas como Cosío Villegas).

El aporte de los intelectuales contribuyó también a legitimar y apuntalar las políticas de los sucesivos gobiernos. Si hay algo que es notorio, es la profunda imbricación e interdependencia entre los sucesivos gobiernos y los intelectuales/ técnicos/ académicos que los apoyaron en la conformación de sus proyectos y emprendimientos.

¿En qué medida se puede decir que tanto los miembros del Ateneo como los de la Generación del 15 fueron intelectuales críticos? En algunos casos, como ya se ha dicho, la frustración de las ambiciones orilló a varios a la búsqueda de nuevos horizontes en el ámbito privado. Otros, dentro de la academia, escribieron ensayos críticos en el marco de una cierta nostalgia por los ideales transformados o perdidos. Otros, como el propio Cosío, desempeñaron cargos académicos y empresariales en la cultura, y criticaron fuertemente a alguno de los gobiernos en turno. La crítica no fue grupal, sino que dependió de las aspiraciones y las posibilidades de cada uno.

¿Fue el Estado mexicano promotor e impulsor de proyectos culturales, académicos, editoriales, disciplinares? Podemos decir que fueron los hombres los que convencieron al Estado, y el Estado, que los necesitaba, reconoció la importancia de sus obras y los apoyó, pero esto es muy variable a lo largo del período, y no hay 
que perder de vista las amistades y relaciones incluso familiares entre ellos ${ }^{36}$, y las confrontaciones personales. Indirectamente, los gobiernos mexicanos, al otorgar becas, enviar a algunos a formarse en el extranjero, o como miembros de las legaciones diplomáticas, coadyuvó a la formación de líderes intelectuales con una cierta cultura cosmopolita; es el caso de los que fueron estudiar tanto a los Estados Unidos, como a Francia o Inglaterra, y al regresar obtuvieron plazas en el gobierno.

Si uno quisiera rastrear los orígenes sociales de estos grupos, quizá se podría aventurar que formaban parte de una clase media "sui generis": algunos provenían de familias acomodadas cuyos parientes desempeñaron, antes que ellos, cargos públicos de importancia, como sería el caso de la familia de Reyes, pero a los que la Revolución perjudicó, ya sea porque los obligó a exiliarse o porque perdieron su posición; otros provenían de la provincia mexicana, de familias a las que la Revolución permitió enviar a sus hijos a escuelas de calidad, como la Nacional Preparatoria o la Escuela de Jurisprudencia, más allá de la participación de los padres en alguno de los bandos durante la gesta revolucionaria, e incluso más allá de la muerte o la falta de alguno de los progenitores. Gómez Morin y Lucio Mendieta son dos casos que ilustran esa situación. Algunos con más recursos económicos, como Lombardo Toledano, otros con padres dedicados a trabajos en servicios (el padre de Vasconcelos trabajaba en Aduanas, el de Cosío Villegas había sido telegrafista y luego Director de telégrafos). Pero todos ellos tuvieron acceso a una relativamente buena educación, para la época, y maestros que los motivaron. Esto implicó que en algunos casos, si bien al inicio de sus vidas no contaran con recursos económicos que permitieran pensarlos como miembros de las clases acomodadas, a través de la educación, que desde ese entonces y hasta bien entrado el siglo xx ha sido un factor de movilidad social ascendente en México, adquirieran el capital cultural y social que los constituyeron en elites intelectuales.

No es posible pensar a la cultura en México sin considerar el aporte sustancial de la migración española. Los transterrados españoles, como ha dado en llamárseles, coadyuvaron de manera importantísima al surgimiento y consolidación de algunas de las empresas culturales más importantes de la época y su impronta se extiende a todo el siglo xx. La articulación e imbricación de la producción entre los intelectuales españoles y los mexicanos, sobre todo con los de la Generación del 15, más las relaciones de los diversos grupos intelectuales con los sucesivos gobiernos mexicanos, fueron origen y sustento de publicaciones, enseñanza e instituciones culturales que marcaron la historia de la cultura en México.

36. Vasconcelos/Alfonso Reyes; Cosío Villegas/Eduardo Villaseñor; Alfonso Caso/Lombardo/Henríquez Ureña; Gómez Morin/González Casanova; son algunos ejemplos de relaciones de amistad y parentesco que incidieron profundamente en las empresas culturales a las que se dedicaron, pero hay muchos más. 
Referencias Bibliográficas

Cosío Villegas, Daniel. (1947), "La crisis de México". Cuadernos Americanos, xxxiII: 2951, mayo-abr.

Garciadiego, Javier. (2015), Autores, editoriales, instituciones y libros: estudios de historia intelectual. Ciudad de México, El Colegio de México.

(2015), “Alfonso Reyes y La Casa de España en México". In: Valero Pie, Aurelia (ed.). Los empeños de una casa: actores y redes en los inicios de El Colegio de México, 1940-1950. Ciudad de México, El Colegio de México.

Girola, Lidia \& Olvera, Margarita. (1995), "La sociología en México en los años 40 y 50". In: Medina, Camero Verónica (coord.). Estudios de Teoría e Historia de la Sociología en México. Ciudad de México, Unam/uam.

GonzÁlez Neira, Ana (2009), “Cuadernos Americanos y el exilio español: nacimiento de una revista universal (1942-1949). Cuadernos Americanos, 127: 11-30.

Krauze, Enrique, ([2001] 2015), Daniel Cosio Villegas: una biografía intelectual. Ciudad de México, Tusquets Editores.

. ([1976] 2014), Caudillos culturales en la Revolución Mexicana. Ciudad de México, Tusquets.

LOAEZA, Soledad. (2010), "Modernización autoritaria a la sombra de la superpotencia, 19441968". In: Varios Autores. Nueva historia general de México. Ciudad de México, El Colegio de México.

Martínez Assad, Carlos. (2015), "El sexenio alemanista: optimismo y represión”. Relatos e Historias en México, año viI, 82: 42-55.

Meyer, Lorenzo. (2015), “Don Daniel, su México y su Colegio de México”. In: Valero Pie, Aurelia (ed.). Los empeños de una casa: actores y redes en los inicios de El Colegio de México, 1940-1950. Ciudad de México, El Colegio de México.

. ([2000] 2009), "La institucionalización del nuevo régimen". In: VARIos Autores. Historia general de México. Ciudad de México, El Colegio de México. ([2000] 2009), "De la estabilidad al cambio". In: VArios Autores. Historia general de México. Ciudad de México, El Colegio de México.

Monsiváis, Carlos. (2000), "Notas sobre la cultura mexicana en el siglo Xx". In: VARIos Autores. Historia general de México. Ciudad de México, El Colegio de México.

Olvera, Margarita. (2004), Lucio Mendieta y Núñez y la institucionalización de la sociología en México, 1939-1965. Ciudad de México, uam/Miguel Ángel Porrúa, Grupo Editorial. . (2013), Economía y sociología en México: revistas especializadas, liderazgos y procesos de institucionalización, 1928-1959. Ciudad de México, UAm Azcapotzalco.

Niblo, Stephen. (1999), Mexico in the 1940's: modernity, politics, and corruption. Wilmington, Delaware, Scholarly Resources. 
Quintanilla, Susana. (2010), "La educación en México durante el periodo de Lázaro Cárdenas (1934-1940)”. Disponible en: http: //biblioweb.tic.unam.mx/diccionario/htm/articulos/ sec_31.htm, consultado el 10/10/2015.

Tierno Tejera, Sofía (2010), "Colaboraciones de exiliados españoles en las revistas Cuadernos Americanos y El Hijo Pródigo: América como utopía”. Ponencia en el Ix Congreso Argentino de Hispanistas "El Hispanismo ante el Bicentenario". La Plata, Argentina. Disponible en: http://ixcah.fahce.unlp.edu.ar, consultado el 10/10/2015.

Valero Pie, Aurelia (ed.). (2015), Los empeños de una casa. Actores y redes en los inicios de El Colegio de México, 1940-1950. Ciudad de México, El Colegio de México.

Wilkie, James \& Wilkie, Edna Monzón de. (1995), Frente a la Revolución Mexicana: 17 protagonistas de la etapa constructiva. Entrevistas de historia oral. Ciudad de México, UAM, vol. 1. . (2001), Frente a la Revolución Mexicana: 17 protagonistas de la etapa constructiva. Entrevistas de historia oral. Ciudad de México, UAM, vol. 2.

\section{Resumen}

La crisis como oportunidad - grupos intelectuales y la construcción del Estado post-revolucionario: su contexto político e intelectual (1934-1950)

El objeto de este trabajo es proporcionar un panorama del contexto político e intelectual de los años de construcción del Estado mexicano y algunas importantes instituciones y empresas culturales, después de la Revolución. Espero mostrar la relación entre los distintos gobiernos, y diferentes grupos de intelectuales en el periodo, y cómo se dio algo que es característico de México y que quizá lo diferencie de otros países en América Latina: la profunda imbricación entre los gobiernos posrevolucionarios y la participación de los intelectuales en cargos tanto académicos, como técnicos y políticos.

Palabras claves: Revolución Mexicana; Intelectuales; Mercado cultural; Ciencias Sociales. 


\section{Resumo}

A crise como oportunidade - grupos intelectuais e a construção do Estado pós-revolucionário: seu contexto político e intelectual (1934-1950)

O objetivo deste trabalho é fornecer uma visão geral do contexto político e intelectual dos anos de construção do Estado mexicano e algumas importantes instituições e empresas culturais, após a Revolução Mexicana. A relação entre os três governos diferentes, diferentes grupos de intelectuais no período, o seu papel na formação do Fondo de Cultura Economica, Cuadernos Americanos e Revista Mexicana de Sociologia mostrado e como eles deram algo que é característico do México e talvez você além de outros países da América Latina: uma profunda interação entre os governos revolucionários e participação de intelectuais em posições acadêmicas, técnicas e políticas. Palavras-chave: Intelectuais; Empresas culturais; México 1934-1950.

\section{Abstract}

Crisis as opportunity - intellectuals and State in México (1934-1950)

The purpose of this paper is to give an overview of the political and intellectual context during the formative years of both the Mexican state and some important institutions and cultural enterprises after the Mexican Revolution. I will explain the relationship between three different governments and different intellectual groups of this historical period, as well as the role that these groups played in the creation of the Fondo de Cultura Económica, the journal Cuadernos Americanos, and the journal Revista Mexicana de Sociologia. I will also explain the profound interdependence of Post-Revolutionary governments and the participation of intellectuals in academic, technical and political positions. This is characteristic of Mexico and differentiates Mexico from other countries in Latin America.

Keywords: Intellectuals; Cultural enterprises; Mexico 1940-1950.

Texto recebido em 29/2/2016 e aprovado em 16/3/2016. DoI: 10.11606/0103-2070. TS.2016.111600.

LIDIA GIRola es profesora del Departamento de Sociología en el Universidad Autónoma Metropolitana-Azcapotzalco.E-mail: lgirola2000@yahoo.com. 


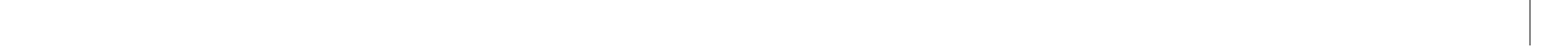

